\title{
Rapid and Enhanced Liquefaction of Pulp from Mango (Mangifera indica L.) cv. Totapuri Using Ultrasound-Assisted Enzyme Pretreatment
}

\author{
Lebaka Veeranjaneya Reddy $^{1}$ (D) Young-Min Kim ${ }^{2, *}$ and Young-Jung Wee ${ }^{3, *(\mathbb{D})}$ \\ 1 Department of Microbiology, Yogi Vemana University, Kadapa (A.P.) 516003, India; lvereddy@gmail.com \\ Department of Food Science \& Technology, Chonnam National University, Gwangju 61186, Korea \\ 3 Department of Food Science and Technology, Yeungnam University, Gyeongsan, Gyeongbuk 38541, Korea \\ * $\quad$ Correspondence: u9897854@jnu.ac.kr (Y.-M.K.); yjwee@ynu.ac.kr (Y.-J.W.); Tel.: +82-53-810-2951 (Y.-J.W.)
}

Received: 12 May 2020; Accepted: 18 June 2020; Published: 20 June 2020

check for updates

\begin{abstract}
The effect of ultrasound and enzyme pretreatment (with pectinase, amylase, and cellulase) on the physicochemical properties (yield, viscosity, total soluble solids, and total phenolics) of mango juice was evaluated through a set of six experiments. Ultrasonication treatment alone showed no influence on juice yield $(54.6 \pm 1.1 \%)$. However, the combined uses of ultrasonication with a pectinase or the enzyme mixture significantly increased the yield $(94.1 \pm 1.4 \%$ and $80.0 \pm 2.1 \%$, respectively) and decreased the enzyme pretreatment time (from $2 \mathrm{~h}$ to $1 \mathrm{~h}$ ). Pectinase treatment assisted by ultrasonication was more effective with regard to juice yield, viscosity reduction, and the clarity of the juice than the enzyme mixture treatment with ultrasonication. Ultrasonication alone significantly increased the amount of total phenolics $(65.5 \pm 1.0 \mathrm{mg} / 100 \mathrm{~mL})$ and showed a slight reduction of viscosity and improvement of clarity compared to the control.
\end{abstract}

Keywords: mango pulp; ultrasound; enzymatic treatment; yield; clarity; viscosity

\section{Introduction}

Mango (Mangifera indica L.) is known as the "king of the fruits" and has been cultivated for around 4000 years in India. The global mango production reached $5.1 \times 10^{7}$ MT in 2016 [1]. India was first in mango production, with $2.0 \times 10^{5} \mathrm{MT}$ and Andhra Pradesh (combined) is the largest producer with $4.5 \times 10^{3} \mathrm{MT}$ in 2016. More than twenty-five different mango cultivars are available in India, and they are also widely cultivated worldwide. Mango is highly perishable and available only in the summer season. The popularity of fresh and processed mango products has been increasing, and in 2015-2016, India shipped $3.6 \times 10^{4} \mathrm{MT}$ of mangoes and $1.3 \times 10^{5} \mathrm{MT}$ of mango pulp [1]. From the pulp nectar, products like juice, puree, and mango-based desserts are prepared. The market for value-added mango products has been gradually increasing at the rate of 5\% annually. Due to their high-pulp-yielding trait, Totapuri mangoes are preferred for pulp preparation. Mango-pulp-producing plants generally procure mangoes either from farmers or market yards in sufficient quantities to run the processing plant until the end of the mango season. During the processing, only $60 \%-75 \%$ of pulp is extracted for further use and the remaining $25 \%-40 \%$ is waste [2].

The natural taste and nutritional value present in fruit juices have led to mango juices having a high consumer acceptability [3]. Mango juice has been known to contain plant polyphenols such as anthocyanins, which are considered to have anti-cancer properties [4]. The presence of polysaccharides in mango pulp makes the juice extraction process through conventional hydraulic pressing or centrifugation very difficult [5]. In addition, the type of juice extracted by these methods is turbid and viscous, and it has a high sedimentation rate during storage. This necessitates further 
clarification processes for its use as a ready-to-drink mango beverage. Enzymes, especially carbohydrate hydrolases, can be utilized to extract juice from fruit pulps for an improved and enhanced yield. There are many reports on the utilization of enzymes, including pectinases, cellulases, and amylases, for juice extraction, clarification, liquefaction, maceration, and cloud stabilization [6,7]. These enzymes break down the cell wall and complex structures of fruits and provide maximum juice yields [8].

In the past few decades, ultrasound usage for the extraction of biomolecules from plant materials has garnered significant attention, and enhanced yields and reduction in extraction time have been observed [9]. Ultrasonication has been applied for extracting and increasing juice yield from pulpy fruits like pineapples, bananas, and apples $[8,10,11]$. Santhirasegaram et al. [12,13] studied the effect of ultrasound on the quality attributes of mango juice, but literature on ultrasound-assisted enzymatic juice extraction from mango pulp is limited. Hence, the present study was conducted to determine the effect of ultrasonication and enzyme (amylase, cellulase, and pectinase) treatment on juice yield and the physicochemical characteristics of juice extracted from mango pulp.

\section{Materials and Methods}

Mango fruits were procured from mango fields near Kadapa, Andhra Pradesh, India. The mangoes were cleaned and peeled, and the remaining pulp was cut into small pieces and homogenized with a home mixer and stored in a refrigerator until further utilization.

The mango juice was extracted from the prepared pulp by subjecting it to ultrasonication and enzymatic treatment according to the experimental design below:

T1. Control (no treatment).

T2. Ultrasonication treatment.

T3. Pectinase treatment.

T4. Enzyme cocktail treatment.

T5. Combined sonication and pectinase.

T6. Combined sonication and enzyme cocktail treatment.

For ultrasonication, a VC 250 ultrasonic probe (Sonics \& Materials, Inc., Newtown, CT, USA) was used; $25 \mathrm{~g}$ of the pulp was placed in a $50 \mathrm{~mL}$ glass beaker and subjected to ultrasonication. The equipment was operated under a self-programming mode of $15 \mathrm{~s}$ on and $5 \mathrm{~s}$ off for $5 \mathrm{~min}$ at $24 \mathrm{kHz}$ with $250 \mathrm{~W}$ power. The temperature of the pulp was maintained by keeping the beaker in an ice bath. After sonication, $0.2 \%$ of the selected enzymes (pectinase, amylase, and/or cellulase) were added to the pulp, followed by incubation in a rotary shaker for $2 \mathrm{~h}$. Samples were collected every $30 \mathrm{~min}$ for yield and clarity analysis. Amylase and cellulase were purchased from Sigma-Aldrich (St. Louis, MO, USA) and pectinase was procured from Novozyme (Bagsværd, Denmark). After the ultrasound and enzymatic treatment, the juice was extracted from the pulp using a cheesecloth, and samples were stored at $4{ }^{\circ} \mathrm{C}$ till further analysis.

The yield was calculated by measuring the weight before and after the treatment using the following balance equation:

$$
\text { Yield }(\%)=\frac{\text { Weight of juice recovered }}{\text { Weight of pulp taken }} \times 100
$$

The viscosity of the extracted juice was determined using a DV2T cone and plate viscometer (Brookfield Engineering Laboratories, Inc., Middleboro, MA, USA) at $10 \mathrm{rpm}$. The results are presented in centipoise $(\mathrm{cP})$. The clarity of the extracted juice was determined by measuring the percentage transmittance (\% T) at $640 \mathrm{~nm}$ using a UV-1800 spectrophotometer (Shimadzu, Kyoto, Japan). The total soluble sugar (TSS) of the extracted juices was determined using a digital portable refractometer (Hanna Instruments Inc., Woonsocket, RI, USA). Total polyphenols of the juice samples were estimated using the Folin-Ciocalteu assay $[14,15]$. 
All treatments and analyses were carried out in triplicate, and the data presented here are reported as the mean values \pm standard deviations (SDs). SPSS ver. 11.0 was used for the analysis of variance.

\section{Results and Discussion}

The observed results are shown in Table 1. The yield of mango juice from the pulp increased in pectinase-treated (T3) samples, compared to all the other study treatments. This may be because of the low content of starch and cellulose and the very high content of pectin in mango pulp $[7,16]$. Pectin in fruit works as a binding agent, and has juice-holding capacity. To extract juice from fruit pulp and reduce subsequent viscosity, the breakdown of the complex pectin structure is essential. Ultrasonication alone (T2) did not show much effect on increasing juice yield, but in combination with enzymatic pretreatments (T5 and T6), it acted synergistically with the enzymes, resulting in a significantly increased yield when compared to treatments T3 and T4. Ultrasound pretreatment with enzymatic pretreatment (T5) resulted in the highest juice yield of $94.40 \%$, and this was $125 \%$ greater than the yield observed in case of the control treatment and 50\% higher than that observed in case of the enzymatic treatment (T4) alone. This observation suggests that ultrasound may help in the formation of acoustic cavitation, which promotes the breakdown of fruit tissue and cell wall structure, which subsequently enables enzyme accessibility to their substrates $[8,17,18]$. However, when ultrasound was applied alone, it was not able to sufficiently degrade the cell wall components of the mango pulp nor extract a satisfactory amount of juice; hence, when compared to the control (T1), there was no large difference in yield [19]. Lieu and Le [20] recently reported a marked increase in juice yield by the sonication of grape mash. These results suggest that ultrasonication alone is enough for the extraction of juices from the fruits that have low pectin concentrations. Enzymatic treatments T3 and T4 showed a highly significant increase in juice yield from the mango pulp following a $2 \mathrm{~h}$ incubation period. Pectinase treatment (T3) alone released $88 \%$ of the juice from the mango pulp, which was the highest observed yield following a single treatment in the present study. The enzyme mixture treatment (T4) significantly increased juice yield, with a 70\% yield from mango pulp, when compared to the control treatment and ultrasonication alone. Our results are in agreement with those of many previous reports, which showed the improvement of juice yields following the treatment of grapes, pineapples, bananas, and apples with pectinolytic and cell-wall-degrading enzymes [8,10,11].

Table 1. Effect of ultrasonication and enzyme treatments on the yield and physicochemical properties of Totapuri mango juice.

\begin{tabular}{|c|c|c|c|c|c|c|}
\hline Treatment No. & Treatment Method & Yield (\%) & Viscosity (cP) & Clarity $(\% \mathrm{~T})$ & TSS $\left({ }^{\circ}\right.$ Brix $)$ & Total Phenolics $(\mathrm{mg} / 100 \mathrm{~mL})$ \\
\hline $\mathrm{T} 1$ & Control & $35.4 \pm 1.2^{f}$ & $25.4 \pm 0.2^{a}$ & $20.2 \pm 2.5^{f}$ & $13.0 \pm 0.4^{d}$ & $40.0 \pm 1.5^{f}$ \\
\hline $\mathrm{T} 2$ & Ultrasonication & $54.6 \pm 1.1^{e}$ & $23.1 \pm 1.0^{b}$ & $30.5 \pm 1.2^{e}$ & $14.1 \pm 0.2^{c}$ & $65.5 \pm 1.0^{c}$ \\
\hline $\mathrm{T} 3$ & Pectinase & $86.0 \pm 2.4^{b}$ & $3.56 \pm 1.2^{f}$ & $70.5 \pm 3.8^{b}$ & $15.2 \pm 0.5^{b}$ & $60.0 \pm 0.8^{d}$ \\
\hline $\mathrm{T} 5$ & Ultrasonication + Pectinase & $94.1 \pm 1.4^{a}$ & $5.9 \pm 0.4^{e}$ & $78.7 \pm 4.3^{a}$ & $16.8 \pm 0.5^{a}$ & $80.8 \pm 0.7^{a}$ \\
\hline T6 & Ultrasonication + enzyme mix & $80.0 \pm 2.1^{c}$ & $10.5 \pm 0.8^{d}$ & $58.6 \pm 1.2^{c}$ & $15.0 \pm 0.2$ & $68.0 \pm 1.3^{b}$ \\
\hline
\end{tabular}

Letters a-f denote statistical significance at $p<0.05$. TSS: total soluble sugar.

The important finding in the present study is that ultrasonication, when used in combination with pectinase (T5), drastically decreased the time of pectinase treatment required. This treatment method helped in the clarification of the juice within half $(1 \mathrm{~h})$ of the selected time duration (i.e., $2 \mathrm{~h}$ ), and showed a juice yield of $85 \%$ (Figure 1 ). The effect of pectinase concentration on juice yield in combination with ultrasound was also studied; these results are shown in Figure 2. It was observed that $0.15 \%$ enzyme treatment yielded $80 \%$ of juice after $2 \mathrm{~h}$ of incubation. This finding supports the potential improvement of juice quantity and quality within a shorter duration with low enzyme loading. In addition to this, the combination of ultrasonication with enzyme mixture treatment (T6) drastically improved the quantity of mango juice compared to the enzyme mixture alone, and this could be utilized as an alternative method for juice extraction from mango pulp. 


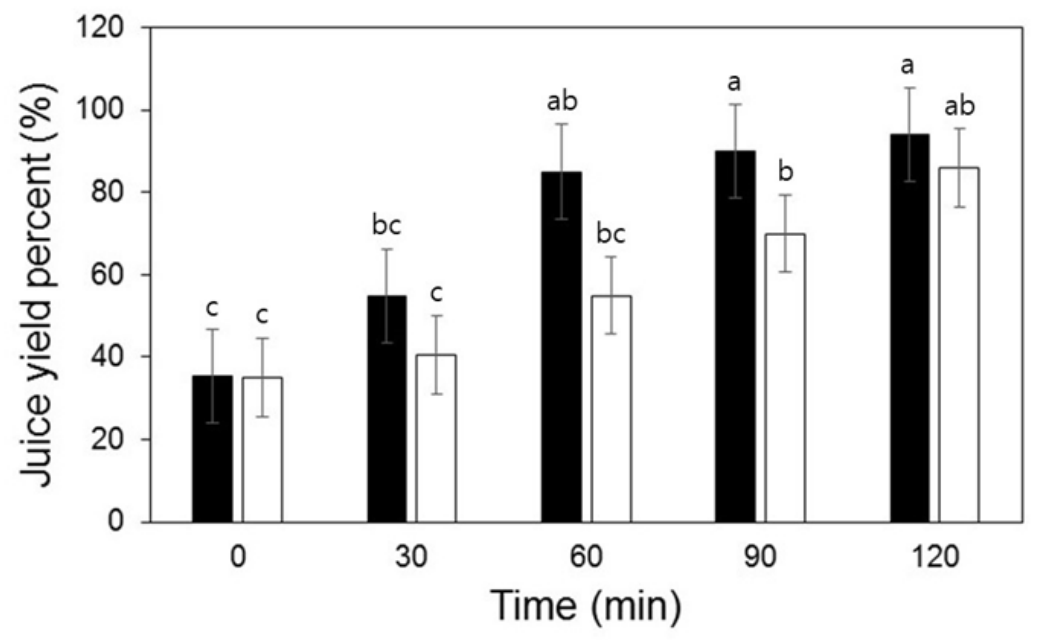

Figure 1. Effect of incubation time on mango juice yield following the treatments with the combination of ultrasonication and pectinase (T5) and pectinase alone (T4). $\mathbf{n}$, Combination of ultrasonication and pectinase treatment (T5); $\square$, Pectinase alone treatment (T4). Values are presented as means, and error bars represent SD. Letters a-c denote statistical significance at $p<0.05$.

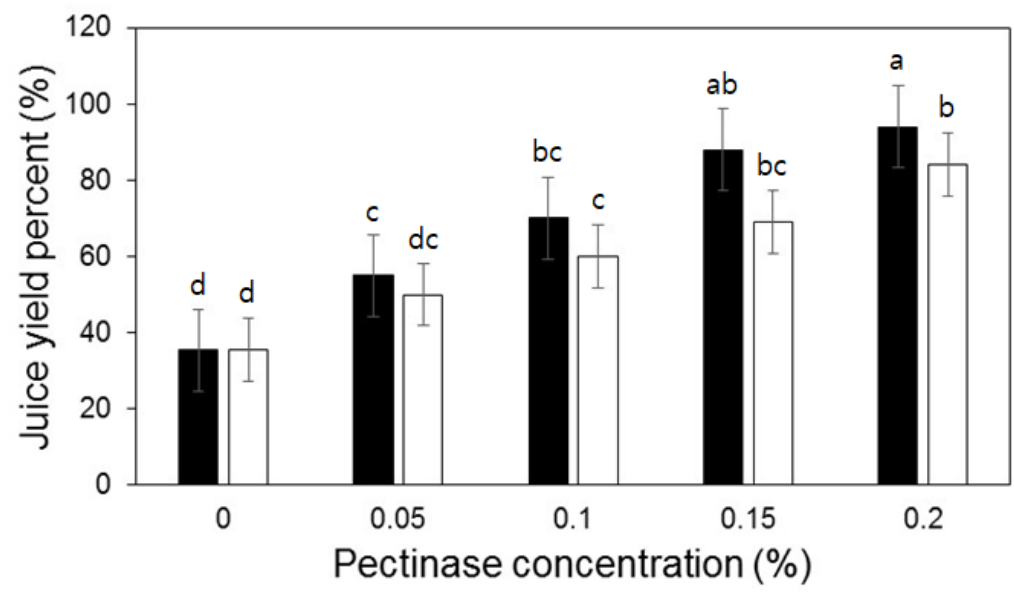

Figure 2. Effect of pectinase concentration on mango juice yield following treatments with the combination of ultrasonication and pectinase (T5) and pectinase alone (T4). $\mathbf{n}$, Combination of ultrasonication and pectinase treatment (T5); $\square$, Pectinase alone treatment (T4). Values are presented as means, and error bars represent SD. Letters a-d denote statistical significance at $p<0.05$.

Viscosity is a critical parameter of fruit juices that affects their rheological properties. In the present study, ultrasonication did not significantly decrease the viscosity of mango juice compared to the control (i.e., viscosity decreased from $25.4 \pm 0.2 \mathrm{cP}$ to $23.1 \pm 1.0 \mathrm{cP}$ ). However, the viscosity of mango juice was significantly decreased by enzymatic treatments ( $\mathrm{T} 3$ and $\mathrm{T} 4$; from $25.4 \pm 0.2 \mathrm{cP}$ to $3.56 \pm 1.2 \mathrm{cP}$ and $18.4 \pm 0.6 \mathrm{cP}$, respectively) and combined enzymatic treatments with ultrasonication (T5 and T6; from $25.4 \pm 0.2 \mathrm{cP}$ to $5.9 \pm 0.4 \mathrm{cP}$ and $10.5 \pm 0.8 \mathrm{cP}$, respectively). Pectinase treatment (T3) significantly decreased the juice viscosity compared to the enzyme mixture treatment (T4) because pectin is a key molecule responsible for viscosity, and the pectinolytic activity of pectinase effectively decreased the viscosity of the juice by breaking down the pectin into pectic acid, methanol, and oligogalacturonates. The viscosity reduction profiles are based on the composition of fruit pulp. The results of the present investigation are in accordance with the previous report by Costa et al. [21], who also found decreased viscosity of pineapple juice due to the lysis of pectin by pectinase. The combination of the ultrasound and enzyme mixture treatments dramatically decreased the viscosity of the mango juice compared to 
the enzyme mixture alone. This might be because of the separation of extracted juice from pectin by ultrasonication and following the enzymatic treatments, as reported by Bora et al. [11].

Clarity is an essential and desirable characteristic for fruit juices. In the present investigation, clarity was increased following all the treatments when compared to the control, from $20.2 \pm 2.5$ (T1) to $70.5 \pm 3.8$ (T2), $30.5 \pm 1.2$ (T3), $45.8 \pm 2.4$ (T4), $78.7 \pm 4.3$ (T5), and $58.6 \pm 1.2$ (T6). Pectinase treatment (T3) and its combination with ultrasonication (T5) resulted in a very high increase in the clarity of the mango juice, since pectin is the key substance responsible for the cloudiness of the juice, compared to starch and cellulose. Enzyme mixture treatment (T4) and its combination with ultrasonication (T6) significantly increased the clarity of the juice compared to the control (T1) because starch and cellulose present in the pulp were degraded. Ultrasound along with the enzymatic treatments ( $\mathrm{T} 5$ and $\mathrm{T} 6$ ) resulted in significant improvement in clarity compared to when the treatments were applied independently. Similar results were obtained with pectinase-treated banana juice and orange juice, whereby clarity was significantly improved by the combination of ultrasound and pectinase treatments [22,23]. Santhirasegaram et al. [12] reported a significant improvement in the clarity of mango juice following ultrasonication; similarly, Abid et al. [24] and Bora et al. [11] achieved very high clarity in apple and banana juices following sonication and enzymatic treatments, respectively.

Total soluble sugar (TSS) is the most important parameter in determining the taste and consumer acceptability, because this provides sweetness to the produced juice. The content of TSS in the juices obtained following treatments T2, T3, T4, T5, and T6 increased by $14.1 \%, 15.2 \%, 14.6 \%, 15.8 \%$, and $15.0 \%$, respectively, in comparison with the control sample (T1). Even though the yield was low in the case of the ultrasonication treatment (T2) and the combined ultrasonication and pectinase treatment (T5), the TSS content in T5 was higher. The reason for this could be that T5 generated increased juice volume along with an increased release of bound soluble sugars from the complex molecules. In the combined treatment, the ultrasound helped in increasing the TSS contents further via the random breakdown of the cell wall structures, which enabled the higher accessibility of the cell wall components for the enzymes [20]. When compared with the juices obtained following the T3 and T5 treatments, the TSS levels were low in those obtained following the T4 and T6 treatments. This may be due to the unavailability of high concentrations of starch and cellulose.

Phenolic compounds play a significant role in providing color and stabilizing the organoleptic properties of juices. In the present study, total phenolic content was improved following all treatments; the juices obtained following all treatments contained significantly higher total phenol contents $(65 \%, 50 \%, 45 \%, 100 \%$, and $70 \%$ increase in the phenol contents of the juices obtained following the $\mathrm{T} 2, \mathrm{~T} 3, \mathrm{~T} 4, \mathrm{~T} 5$, and $\mathrm{T} 6$ treatments, respectively, compared to the control). The results showed that ultrasonication alone was very effective in extracting more phenolics than the pectinase (T3) and enzyme mixture treatments (T4). The combination of ultrasonication with pectinase and the enzyme mixture treatments dramatically increased the total amount of phenolics extracted compared to the treatment with pectinase and the enzyme mixture alone. Our results validate the previous studies on pineapple, grape, and apple juice obtained via ultrasound and enzymatic treatments, whereby a higher release of carotenoids, anthocyanins, and total phenolics was achieved [8,20-24]. In fruit pulps and peels, phenolic compounds are bound with many polysaccharides and proteins, and the depolymerization of such complex structures releases them into the juice. The higher phenolic contents of juices obtained from ultrasound-treated samples suggest that the random degradation of cell wall compounds is more essential than the specific action of certain enzymes.

From the results reported here, it can be concluded that pectinase may be more effective than the ultrasonication and enzyme mixture (amylase and cellulase) treatment. With regard to all the parameters tested, except for TSS, ultrasonication showed a significant effect. In combination with the three enzymes, ultrasonication synergistically aided the extraction of juice and functional compounds from mango pulp and shortened the extraction time. The physicochemical characteristics of the juices obtained in this study support that pectinase treatment is necessary for producing high-quality ready-to-serve juice from mango pulp and that the combination with ultrasonication increased the 
functional quality of the juice. Furthermore, our findings also suggest that ultrasonication and enzyme mixture treatments alone are not sufficient to obtain high-quality juice from mango pulp. However, it can be concluded that the combination of ultrasonication with the enzyme mixture drastically increased the quality of the mango juice, and this combination could be adapted as an alternative method for juice extraction from mango pulp. In addition, it is essential to optimize various parameters such as time, temperature, frequency, and amplitude of sonication treatment in the future to understand the mechanisms underlying their effects on mango juice extraction.

Author Contributions: Conceptualization, L.V.R. and Y.-J.W.; experimental work, L.V.R.; formal analysis, L.V.R., Y.-M.K., and Y.-J.W.; writing-original draft preparation, L.V.R.; writing—review and editing, Y.-M.K., and Y.-J.W.; project administration, Y.-J.W.; funding acquisition, Y.-J.W. All authors have read and agreed to the published version of the manuscript.

Funding: This research was supported by the 2018 Yeungnam University Research Grant, grant number 218A380157.

Acknowledgments: L.V.R. thanks the Yogi Vemana University authorities for their generous sanction of study leave.

Conflicts of Interest: The authors declare no conflict of interest.

\section{References}

1. APEDA (Agricultural \& Processed Food Products Export Development Authority), Ministry of Commerce \& Industry, Government of India. Available online: http://apeda.gov.in/apedawebsite/six_head_product/ PFV_OPF.htm (accessed on 17 October 2019).

2. Reddy, L.V.; Reddy, O.V.S.; Wee, Y.J. Production of ethanol from mango (Mangifera indica L.) peel by Saccharomyces cerevisiae CFTRI10. Afr. J. Biotechnol. 2011, 10, 4183-4189.

3. Rivera, A.P.; Cabornida, I.M.B. Development of ready-to-drink green mango juice. USM R D J. 2008, 16, 71-77.

4. Ribeiro, S.M.R.; de Queiroz, J.H.; de Queiroz, M.E.L.R.; Campos, F.M.; Sant'ana, H.M.P. Antioxidant in mango (Mangifera indica L.) pulp. Plant Food Hum. Nutr. 2007, 62, 13-17. [CrossRef] [PubMed]

5. Sagu, S.T.; Nso, E.J.; Karmakar, S.; De, S. Optimisation of low temperature extraction of banana juice using commercial pectinase. Food Chem. 2014, 151, 182-190. [CrossRef]

6. Chauhan, S.K.; Tyagi, S.M.; Singh, D. Pectinolytic liquefaction of apricot, plum, and mango pulps for juice extraction. Int. J. Food Prop. 2001, 4, 103-109. [CrossRef]

7. Ghosh, U.; Gangopadhyay, H. Studies on the extraction of mango juice (Himsagar Variety) using enzymes from A. oryzae. Indian J. Chem. Technol. 2002, 9, 130-133.

8. Nguyen, T.P.; Le, V.V.M. Application of ultrasound to pineapple mash treatment in juice processing. Int. Food Res. J. 2012, 19, 547-552.

9. Vilkhu, K.; Mawson, R.; Simons, L.; Bates, D. Applications and opportunities for ultrasound assisted extraction in the food industry-A review. Innov. Food Sci. Emerg. Technol. 2014, 9, 161-169. [CrossRef]

10. Quang, P.S.; Le, T.T.T.; Le, V.V.M. Optimization of ultrasonic treatment of apple (Malus domestica) mash in the extraction of juice with high antioxidant content. IOSR J. Eng. 2014, 4, 18-21. [CrossRef]

11. Bora, S.J.; Handique, J.; Sit, N. Effect of ultrasound and enzymatic pre-treatment on yield and properties of banana juice. Ultrason. Sonochem. 2017, 37, 445-451. [CrossRef]

12. Santhirasegaram, V.; Razali, Z.; Somasundram, C. Effects of thermal treatment and sonication on quality attributes of Chokanan mango (Mangifera indica L.) juice. Ultrason. Sonochem. 2013, 20, 1276-1282. [CrossRef] [PubMed]

13. Santhirasegaram, V.; Razali, Z.; Somasundram, C. Effects of sonication and ultraviolet-C treatment as a hurdle concept on quality attributes of Chokanan mango (Mangifera indica L.) juice. Food Sci. Technol. Int. 2015, 21, 232-241. [CrossRef] [PubMed]

14. Singleton, V.L.; Joseph, A.; Rossi, J.R.J.A. Colorimetry of total phenolics with phosphomolybdicphosphotungstic acid reagents. Am. J. Enol. Vitic. 1965, 16, 144-158.

15. Reddy, L.V.; Kim, Y.M.; Yun, J.S.; Ryu, H.W.; Wee, Y.J. L-Lactic acid production by combined utilization of agricultural bioresources as renewable and economical substrates through batch and repeated-batch fermentation of Enterococcus faecalis RKY1. Bioresour. Technol. 2016, 209, 187-194. [CrossRef] [PubMed] 
16. Ali, J.Z.M.; Chin, L.H.; Lazan, H. A comparative study on wall degrading enzymes, pectin modifications and softening during ripening of selected tropical fruits. Plant Sci. 2004, 167, 317-327. [CrossRef]

17. Reddy, L.V.A.; Reddy, O.V.S. Effect of enzymatic maceration on synthesis of higher alcohols during mango wine fermentation. J. Food Qual. 2009, 32, 34-47. [CrossRef]

18. Wu, L.; Lin, F.; Chau, F.T. Ultrasound-assisted extraction of ginseng saponins from ginseng roots and cultured cells. Ultrason. Sonochem. 2001, 8, 347-352. [CrossRef]

19. Vinatoru, M. An overview of the ultrasonically assisted extraction of bioactive principles from herbs. Ultrason. Sonochem. 2001, 8, 303-313. [CrossRef]

20. Lieu, L.N.; Le, V.V.M. Application of ultrasound in grape mash treatment in juice processing. Ultrason. Sonochem. 2010, 17, 273-279. [CrossRef]

21. Costa, M.G.M.; Fonteles, T.V.; de Jesus, A.L.T.; Almeida, F.D.L.; de Miranda, M.R.A.; Fernandes, F.A.N.; Rodrigues, S. High-intensity ultrasound processing of pineapple juice. Food Bioprocess Technol. 2013, 6, 997-1006. [CrossRef]

22. Barman, S.; Sit, N.; Badwaik, L.S.; Deka, S.C. Pectinase production by Aspergillus niger using banana (Musa balbisiana) peel as substrate and its effect on clarification of banana juice. J. Food Sci. Technol. 2015, 52, 3579-3589. [CrossRef] [PubMed]

23. Valero, M.; Recrosio, N.; Saura, D.; Muñoz, N.; Martí, N.; Lizama, V. Effects of ultrasonic treatments in orange juice processing. J. Food Eng. 2007, 80, 509-516. [CrossRef]

24. Abid, M.; Jabbar, S.; Wua, T.; Hashim, M.M.; Hua, B.; Lei, S.; Zeng, X. Sonication enhances polyphenolic compounds, sugars, carotenoids and mineral elements of apple juice. Ultrason. Sonochem. 2015, 21, 93-97. [CrossRef] [PubMed]

(C) 2020 by the authors. Licensee MDPI, Basel, Switzerland. This article is an open access article distributed under the terms and conditions of the Creative Commons Attribution (CC BY) license (http://creativecommons.org/licenses/by/4.0/). 